\title{
Intracellular calcite and sulfur dynamics of Achromatium cells observed in a lab-based enrichment and aerobic incubation experiment
}

\author{
Tingting Yang $\mathbb{D} \cdot$ Andreas Teske $\cdot$ Wallace Ambrose $\cdot$ Verena Salman-Carvalho $•$ \\ Robert Bagnell $\cdot$ Lars Peter Nielsen $(\mathbb{C}$
}

Received: 5 March 2018/Accepted: 26 August 2018/Published online: 7 September 2018

(C) Springer Nature Switzerland AG 2018

\begin{abstract}
We investigated the intracellular dynamics of calcite and sulfur in the large sulfur-oxidizing, calcite-accumulating bacterium Achromatium, with an emphasis on oxygen exposure as a physiological control. For this purpose, morphological changes and possible accretion mechanisms of calcite granules in cells that were freshly collected from natural Achromatium-containing sediment were compared to cells from the same source after prolonged exposure to atmospheric oxygen. Intracellular sulfur is oxidized
\end{abstract}

Electronic supplementary material The online version of this article (https://doi.org/10.1007/s10482-018-1153-2) contains supplementary material, which is available to authorized users.

T. Yang $\cdot$ A. Teske

Department of Marine Sciences, University of North

Carolina at Chapel Hill, Chapel Hill, USA

W. Ambrose

Department of Applied Physical Sciences, University of

North Carolina at Chapel Hill, Chapel Hill, USA

V. Salman-Carvalho

HGF MPG Joint Research Group for Deep-Sea Ecology

and Technology, Max Planck Institute for Marine

Microbiology, Bremen, Germany

R. Bagnell

Microscopy Services Laboratory, University of North

Carolina at Chapel Hill, Chapel Hill, USA and removed in response to oxygen exposure. Calcite granules also undergo distinct oxygen-related dynamics; they alternate between tightly packaged, smooth granules with narrow but sharply defined interstitial spaces in atmospheric oxygen-exposed cells, and more loosely packaged granules with irregular, bumpy surface texture and larger interstitial spaces in cells that were not artificially exposed to oxygen. These results suggest that morphological changes of the calcite granules reflect their changing physiological role inside the cell. Sulfur oxidation and calcite dissolution appear to be linked in that proton generation during sulfur oxidation is buffered by gradual calcite erosion, visible in the smooth, rounded surface

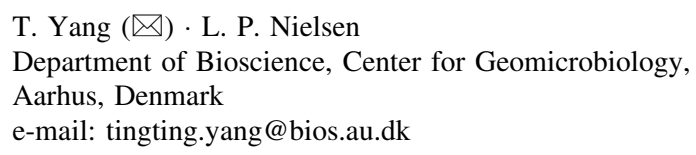


morphology observed after oxygen exposure. Our results support the hypothesis that calcite dynamics buffer the intracellular $\mathrm{pH}$ fluctuations linked to electron acceptor limitation during proton-consuming sulfide oxidation to sulfur, and electron acceptor abundance during proton-generating sulfur oxidation to sulfate.

Keywords Achromatium - Geomicrobiology · Intracellular calcite granules $\cdot$ Redox $\cdot$ Sulfuroxidizing bacteria

\section{Introduction}

The large sulfur-oxidizing bacterium Achromatium is commonly found at the sediment surface in freshwater lakes (Gray and Head 2014). It also occurs in intertidal saltwater pools containing poorly consolidated marine phytodetritus, where the majority of cells cluster around the oxycline near the sediment surface (Salman et al. 2015). Freshwater Achromatium populations migrate along opposing gradients of oxygen and sulfide, where they take up and oxidize sulfide to intracellular sulfur, which is then further oxidized to sulfate (Gray et al. 1997, 1999). Salt marsh populations occurred likewise within diurnally shifting oxygen and sulfide gradients in surficial sediments of an organic-rich tidal pool, consistent with a sulfideoxidizing metabolism (Salman et al. 2015). Metagenomic and genomic sequencing of a freshwater Achromatium population has shown rapidly diversifying and evolving genomes consisting of multiple, non-identical chromosomes within individual Achromatium cells. This highly unusual "decentralized" genome is hypothesized to ensure flexible gene expression and physiological responses throughout the large biovolume of Achromatium cells (Ionescu et al. 2017). Uniquely among sulfur oxidizers and bacteria in general, Achromatium cells contain large intracellular calcite inclusions (West and Griffiths 1913; Head et al. 1996) that are hypothesized to buffer intracellular $\mathrm{pH}$ changes during lithotrophic sulfur oxidation (La Rivière and Schmidt 1992; Salman et al. 2015). The precise function and dynamics of the calcite inclusions remain elusive until today. There are indications that the dynamics of intracellular calcite and sulfur globules in Achromatium reflect oxic/ anoxic cycles during day and night in photosynthetic mats and benthic phytodetritus. Sulfur depletion relative to calcite is associated with surficial, oxidized sediment layers (Lauterborn 1915; Babenzien 1991; Salman et al. 2015), and most likely reflects the aerobic oxidation of intracellular sulfur to sulfate near the sediment surface during the day (Salman et al. 2015). An increase of the relative sulfur content per cell compared to internal calcite was observed either in cells located in anoxic surface sediments at night, or in deeper, permanently anoxic sediment layers that were not affected by daytime activity of photosynthetic cyanobacteria and algae near the sediment surface (Salman et al. 2015). Here, we present an experimental approach to further understand the dynamics of intracellular calcite and sulfur in whole Achromatium cells, and in granule-specific resolution. We examine the morphological changes and possible accretion mechanisms of calcite granules in cells that were freshly picked from natural Achromatium-containing sediment, and compared these to cells from the same source that were incubated under prolonged exposure to atmospheric oxygen before analysis.

\section{Materials and methods}

\section{Sampling}

The sediment sample was collected from an intertidal saltwater pool in Little Sippewissett Salt Marsh in Falmouth, MA $\left(41^{\circ} 34.548^{\prime} \mathrm{N}, 70^{\circ} 38.388^{\prime} \mathrm{W}\right)$ on October 17, 2013 at low tide (Fig. S1a). The surficial sediment in the saltwater pool consisted mostly of unconsolidated phytodetritus; Achromatium populations mainly concentrate within the first centimeter of the sediment surface (Salman et al. 2015), co-occurring with a well-developed accumulation of macroscopic pink-coloured phototrophic consortia that are characteristic of this location (Seitz et al. 1993; Wilbanks et al. 2014). Surficial phytodetritus and underlying deeper sediment were collected using sterilized $60 \mathrm{ml}$ syringes. One liter of water from the same pool was also collected; both water and sediment samples were stored at $4{ }^{\circ} \mathrm{C}$ and transported back to the University of North Carolina at Chapel Hill on the next day. In the home lab, a glass jar was filled with the dark-brown coloured sediment and placed under natural light for approximately $12 \mathrm{~h}$ to allow the resuspended sediment to settle. The jar was 
wrapped with aluminum foil, but remained open at the top to allow gas exchange and light exposure. All incubations were performed at room temperature. To protect the settled sediment from stagnation and extreme sulfide accumulation, tidal dynamics were mimicked by gradually adding oxygenated salt marsh water (collected from the same intertidal pool) to the top of the jar, and draining it from the bottom without disturbing the phytodetritus surface, using a peristaltic pump ( $6 \mathrm{~h}$ per day, at a rate of 10.2 to $12 \mathrm{ml} /$ hour to drain $50-80 \mathrm{ml}$ water), and a nylon mesh to guard the intake. The water level remained at least $1 \mathrm{~cm}$ above the sediment surface at simulated low tide. Sediment sampling commenced after two days of simulated tidal regime. Using a $10 \mathrm{ml}$ syringe, $1 \mathrm{ml}$ sediment samples were collected each time from the surface layer (0-4 mm), and from a combined deep layer (12-16 $\mathrm{mm}$ and 24-28 $\mathrm{mm}$; combining these layers was necessary due to low cell abundance at 24-28 mm). The sampling depths were chosen to include contrasting environmental conditions (Fig. S2a): the dynamic oxygen gradient at the sediment surface that builds up during the daytime due to the photosynthetic activity of algae and cyanobacteria in the phytodetritus, and the anoxic and sulfidic sediment below the surface (Salman et al. 2015). The high porosity of the intertidal muddy sediment and the presence of various aggregate sizes of phytodetritus limited sampling resolution to a $4 \mathrm{~mm}$ layer. Syringe samples collected at night were placed into small plastic petri dishes, where the sediment remained inside the syringes, and the open syringe end was covered by parafilm. This way, the sediment was exposed to atmospheric oxygen penetration for approx. $12 \mathrm{~h}$ before cell collection, microscopy, elemental mapping, and imaging of intracellular S:Ca ratios the next day. Microelectrode measurements after air exposure of $1 \mathrm{ml}$ syringe subsamples in the petri dish revealed fully oxic conditions. Samples collected during the daytime were sorted and imaged without the prolonged oxygen-exposure step in the syringe. The entire sampling procedure was repeated three times, separated by two-day intervals.

Microelectrode profiles

The redox gradients in the Achromatium-rich sediment were measured at Aarhus University. The oxygen, sulfide and $\mathrm{pH}$ profiles of the incubated sediment were measured as described previously (Salman et al. 2015) using the microelectrodes $\mathrm{OX}-100, \mathrm{H}_{2} \mathrm{~S}-100$, and $\mathrm{pH}-$ 100 (Unisense, Aarhus, DK) during the day at simulated low tide (Fig. S2a).

\section{Cell collection}

Each sediment sample was washed through a $23 \mu \mathrm{m}$ pore-size mesh using sterile-filtered marsh water as washing fluid. Most of the larger sediment debris was removed at this step while most Achromatium cells passed through the pores and were collected in a glass petri dish. By a gentle rotating motion of the petri dish, Achromatium cells were concentrated in the center, and subsequently transferred into filter-sterilized marsh water with a thinned-out glass Pasteur pipette. Achromatium cells were washed with sterilized salt marsh water at least three times before SEM sample preparation. As reported previously Salman et al. (2015), the cells were round to oval, with diameters mainly in the range of 20 to $30 \mu \mathrm{m}$ (Fig. S1b-d).

Scanning electron microscopy and energydispersive X-ray spectroscopy (SEM-EDS)

In three samplings separated by two-day intervals each, a total of 125 Achromatium cells were scanned (Table S1). 32 and 25 cells were obtained from the oxycline at the sediment surface and from anoxic subsurface at daytime, respectively; these cells were immediately processed. 32 and 36 cells were collected from surface and subsurface sediment at night, respectively, and exposed to atmospheric oxygen for approx. $12 \mathrm{~h}$ in the sampling syringe before cell collection and processing. The cells were subsequently analyzed for their intracellular sulfur and calcium content. Washed Achromatium cells were arranged on Nucleopore filters $(0.2 \mu \mathrm{m}$ pore size), fastened and simultaneously dried by adding one pipette droplet of hexamethyldisilazane (HMDS, electronic grade, Alfa Aesar ${ }^{\circledR}$ ). A tissue was placed underneath the filter to remove extra HMDS and seawater immediately. After drying, the samples were coated with a 3-nm layer of $\mathrm{Au} / \mathrm{Pd}$ (Cressington Model 108 sputter coater). At the Chapel Hill Analytical and Nanofabrication Laboratory (chanl.unc.edu), imaging was carried out with a Hitachi 4700 Cold Cathode field emission scanning electron microscope, and elemental mapping by energy-dispersive X-ray spectroscopy (EDS) was performed with an INCA PentaFETx3 
instrument (Oxford Instruments, UK) operating at $15 \mathrm{kV}, 12 \mathrm{~mm}$ working distance at adjusted magnification, and a scan time of 100 s per scan. Net Ca and S signals per image give a relative indication of the amounts of $\mathrm{Ca}$ and $\mathrm{S}$ (calculated as weight\%) within the primary beam's penetration depth of ca. $5 \mu \mathrm{m}$. After EDS scanning, entire cells, specific granules, and intergranular space were outlined with the free form line tool (as specified in the INCA Energy Operator Manual; Oxford Instruments, UK) to integrate elemental mapping data from these defined samples and spaces. Since measured sulfur amounts were frequently approaching zero, the results of elemental mapping for $\mathrm{Ca}$ and $\mathrm{S}$ were calculated as $\mathrm{S}:$ Ca ratio (Table $\mathrm{S} 1$ ).

Focused ion beam analysis

To examine the structure of the intracellular calcite inclusions, high-resolution images were obtained by focused ion beam analysis (FIB), performed with a FEI Helios 600 Nanolab Dual Beam FIB System (Hillsboro, OR) at the Chapel Hill Analytical and Nanofabrication Laboratory (chanl.unc.edu). A $30 \mathrm{kV}$ gallium ion beam was used at a tilt of 52 degrees with 28-48 pA beam current. Rectangular wedges were etched into the surface of Achromatium cells yielding partial or near-complete cross sections through the cell and granule. The $\mathrm{x}, \mathrm{y}$ and $\mathrm{z}$ dimensions of the etched area were set to 10-20 Â $\mu \mathrm{m}$, or sometimes at $30 \hat{\mathrm{A}} \mu \mathrm{m}$ depth to attempt higher penetration. FIB milling usually took about 2-5 min.

Time-lapse observation of an air-exposed cell

Freshly collected cells from the oxic or microoxic surface sediments were transferred into a glass bottom petri dish to observe their morphological change over time under oxic conditions. The petri dish was filled with sterile marsh water, covered and placed on the platform of an Olympus IX70 Inverted Live Cell System for $17 \mathrm{~h}$ in dark. To prevent the cells moving out of the observation field, the Achromatium cells were carefully deposited into a $0.5 \mathrm{~cm} \times 0.5 \mathrm{~cm}$ square drawn on the glass bottom by a wax pen. One cell did not roll during the experiment, and made it possible to record changes of the cell and its granules in a time series. Since this stationary cell was morphologically similar to other rolling Achromatium cells, and showed activity by its slightly jerking movement, it should be representative of other Achromatium cells. Phase contrast images were taken every $30 \mathrm{~s}$ (Movie S1). Image analysis was performed by ImageJ (Schneider et al. 2012) to measure the cell area, area integrated intensity, and mean grey value. The background fluorescence was measured three times at different spots on the images. The corrected total cell fluorescence (CTCF) was calculated as follows: $\mathrm{CTCF}=$ integrated density $-($ area of selected cell $\times$ mean fluorescence of background readings).

\section{Results}

Microelectrode survey of Achromatium cellcontaining sediments

The salt marsh sediment sample was incubated by slowly pumping-in and draining-out filtered natural seawater at room temperature. The microelectrode profiles of oxygen, sulfide and $\mathrm{pH}$ measured during daytime and simulated low tide condition (Fig. S2a) revealed gradually increasing total sulfide concentrations (up to $\sim 300 \mu \mathrm{mol} / \mathrm{l}$ ) throughout the deeper sediment layers. Around the sediment surface, the oxygen and sulfide profiles overlapped, but concentrations rapidly decreased to the detection limit. The $\mathrm{pH}$ decreased from 7.85 in the overlying water to a local minimum of 7.1 at $2 \mathrm{~mm}$ sediment depth before increasing again to 7.7 in the deeper sediment. The local $\mathrm{pH}$ decrease indicates efficient sulfur oxidation in these sediment layers as this process releases protons. Since oxygen was already depleted at the depth of the $\mathrm{pH}$ minimum, nitrate-dependent anaerobic sulfur oxidation could occur here (equations in supplementary Online Resource). The irregular topography of the sediment surface made it difficult to define a precise surface horizon. However, the upper $4 \mathrm{~mm}$ constituted a surface layer characterized by surficial oxygen penetration, oxygen depletion just above a local $\mathrm{pH}$ minimum, followed by gradual sulfide accumulation. In contrast, subsurface sediments $(>12 \mathrm{~mm})$ remained consistently sulfidic and anoxic. After one month of incubation, the areal density of Achromatium cells at the top $3 \mathrm{~mm}$ had reached $\sim 230$ cells $\mathrm{mm}^{-2}$; the cells appeared white 
against the olive-brown sediment background (Fig. S2b).

\section{Sulfur to calcium elemental ratios}

It was previously shown that Achromatium cells collected directly from oxygenated surface samples were depleted in sulfur, whereas cells from sulfidic, anoxic sediments were characterized by higher sulfur content (Salman et al. 2015). We manipulated this environmental regime by exposing samples taken from surface and subsurface sediment layers to air for $12 \mathrm{~h}$ to let atmospheric oxygen fully penetrate these samples. After this time, the oxygen concentration in these samples was $\sim 200 \mu \mathrm{M}$, as determined with oxygen microelectrodes. Under these conditions, residual sulfide in the sediment was likely depleted, and intracellular sulfur was expected to be oxidized by Achromatium (Gray et al. 1997), and should not be detectable in EDS measurements, regardless of whether the cells originated from surface or subsurface sediment layers. Indeed, EDS determination revealed that air-exposed cells were depleted in intracellular sulfur. The $\mathrm{S}$ :Ca ratios in the air-exposed Achromatium cells were lower (averages near 0.025 and 0.035 for surface and subsurface cells, respectively) than in the cells that were processed immediately after sampling (Fig. 1, Table S1). Achromatium cells that were collected at the sediment surface and immediately processed without further exposure to atmospheric oxygen showed three to four times higher

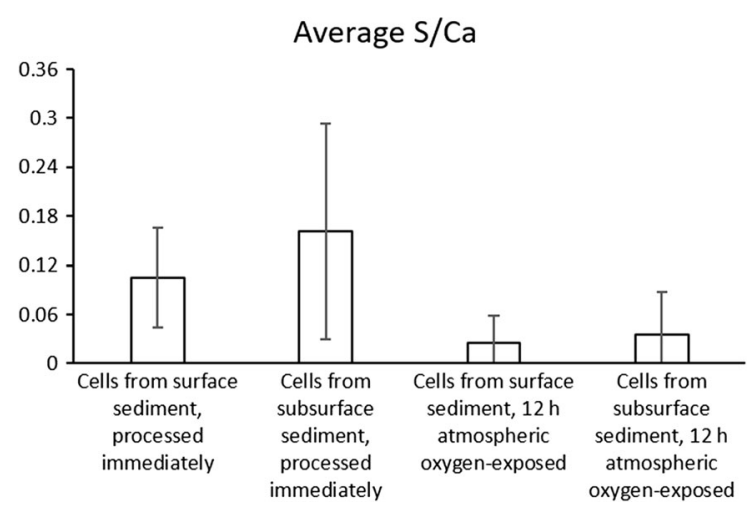

Fig. 1 Elemental ratios of sulfur to calcium in weight $\%$, determined by EDS in cells from surface and subsurface, sampled and processed directly or after exposure to atmospheric oxygen. Averages with standard deviations are plotted here; the full dataset is compiled in Table S1
$\mathrm{S}: \mathrm{Ca}$ ratios (average 0.105); the highest $\mathrm{S}: \mathrm{Ca}$ ratios (average 0.161) occurred in the immediately processed cells from the subsurface sediment (Fig. 1, Table S1). Thus, prolonged post-sampling exposure to atmospheric oxygen exerted a strong effect on $\mathrm{S}: \mathrm{Ca}$ ratios. Closer inspection revealed that the origin of the cells, i.e. from partially oxygenated surficial sediment or anoxic subsurface sediment, did also play a role. Subsurface cells showed a slightly higher S:Ca ratio than their surface counterparts, whether oxygenexposed or not (Fig. 1, Table S1). Cell origin and oxygen exposure seem to have a cumulative effect. The sample set from the most reduced conditions, i.e. freshly sampled subsurface cells, has the highest $\mathrm{S}: \mathrm{Ca}$ ratio, on average 0.161 . Contrasting this, the most oxidized sample set consisting of oxygen-exposed surface cells has the lowest ratio, on average 0.025. The sample sets where sediment origin and oxygen exposure compensate each other to some extent have intermediate $\mathrm{S}: \mathrm{Ca}$ ratios, near 0.035 for oxygenexposed subsurface samples and 0.105 for freshly processed surface samples. Of the two factors, artificial oxygen exposure has a stronger impact on $\mathrm{S}: \mathrm{Ca}$ ratios than the natural redox conditions in the sediment where the cells were collected from, as the entire cohort of freshly sampled, non-exposed cells has consistently higher $\mathrm{S}: \mathrm{Ca}$ ratios than the cohort of oxygen-exposed cells, regardless of origin (Fig. 1, Table S1). Thus, intracellular sulfur dynamics appeared to be controlled by oxygen availability and redox regime. In contrast to the highly dynamic and frequently depleted sulfur pool, calcium was always detectable and highly conspicuous in all cells. Since $\mathrm{S}: \mathrm{Ca}$ ratios do not allow absolute quantifications of both elements, our interpretation of relative sulfur content in relation to oxygen exposure implies that the calcium pool behaves more conservatively than the highly dynamic sulfur pool, and that changes in $\mathrm{S}: \mathrm{Ca}$ ration are generally driven by changes in sulfur content. This interpretation is reasonable given the persistence and visual dominance of calcite granules in all treatments, as shown by microscopic images.

Whole cells, individual small granules and the inter-granule space were further investigated for $\mathrm{Ca}$ and $\mathrm{S}$ signals using SEM/EDS mapping. Freshly sampled non-exposed cells either from the surface or subsurface yielded a strong sulfur signal localized in the interstitial grooves between the large calcite granules (Figs. 2a, 3a, S4a). In contrast, syringe- 

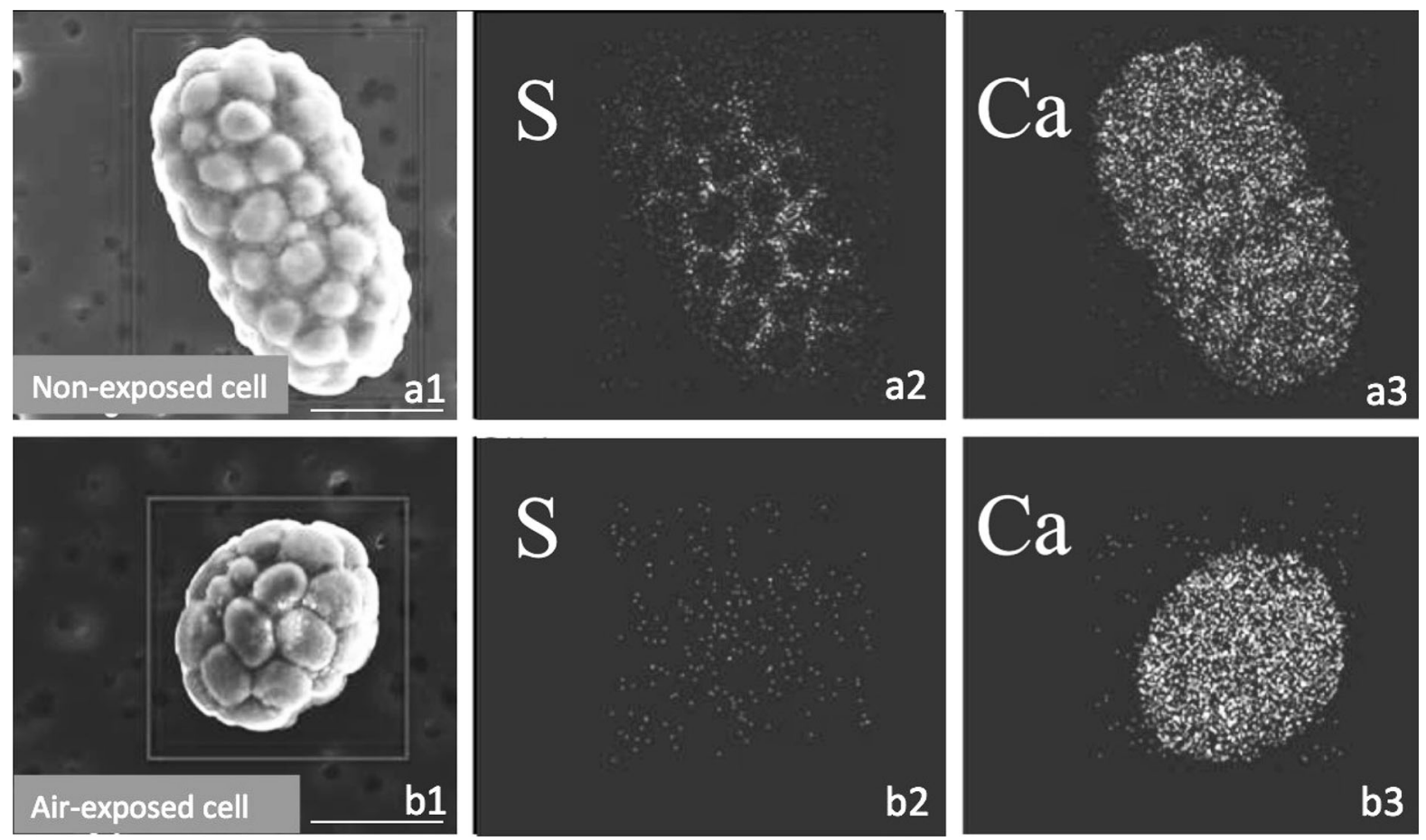

Fig. 2 SEM micrographs and EDS elemental mapping of cells collected at the sediment surface. Panels a1 and b1 show SEM microphotographs of representative cells, panels $\mathbf{a} 2$ and $\mathbf{b 2}$ show the sulfur signal, and panels $\mathbf{a} 3$ and $\mathbf{b 3}$ show the calcium signal for the same cells, respectively. a The cell was not

stored, atmospheric oxygen-exposed cells showed a strongly reduced sulfur signal that was difficult to localize, and close to detection limit anywhere in the cell (Figs. 2b, 3b, S4b), even when cells were sampled from the subsurface, which favors sulfur accumulation (Fig. S4b). Under both conditions, the calcium signals were consistently and easily detectable, however, they appeared more compact in outline in cells after atmospheric oxygen exposure where calcite granules were more tightly packed (Fig. 2b). In cells that did not undergo oxygen exposure calcite granules were less compactly arranged, and separated by wider interstitial grooves (Fig. 2a).

EDS analysis showed that the small granules located in the gaps between the larger calcite granules were composed of calcium (Figs. 3b2, S4b2). While the calcium signal of whole Achromatium cells can be mainly attributed to the large calcite inclusions filling the majority of the intracellular space, the smaller calcium-rich granules may represent $\mathrm{Ca}^{2+}$-rich artificially exposed to air but processed immediately, and shows a distinct sulfur signal as well as calcium. b The cell was treated with prolonged air-exposure, shows barely any sulfur signal and but tightly packed calcium signal across the cell. Scale bar: $20 \mu \mathrm{m}$

inclusions identified recently in these salt marsh Achromatium cells (Salman et al. 2015).

In contrast to previous reports, our visualization of intracellular sulfur via EDS did not reveal an aggregated signal in the form of distinct sulfur globules; the signal was distributed across the interstitial space between the large calcite granules (Fig. 2). Neither whole-cell EDS mapping (Fig. 2) nor localized EDS/ SEM signals (Fig. 3) identified the condensed sulfur signals visible by Raman analysis, or by microscopy as described in Salman et al. (2015). During SEM-EDS preparation the cells had to be treated with hexamethyldisilazane, which may cause unknown chemical alterations. We suspect that HMDS has the potential to damage membrane structures (Cossy and Pale 1987; Pellegata et al. 1978) and cause the diffuse sulfur signal, in particular if the sulfur in Achromatium cells occurs naturally as a membrane-bound colloidal sulfur sol (Steudel 2003). The diffusivity of the sulfur signal in the interstitial space between the calcite granules may therefore represent a preparation artifact. While 
Fig. 3 SEM-EDS spectra for whole cells, granules and the interstitial space

between granules, measured within the outlined areas.

a Measurement of an entire cell collected and processed directly from surface sediment (a1), an individual granule within the cell (a2), and the interstitial space between granules (a3). b Measurement of an entire cell harvested from surface sediment, and measured after prolonged atmospheric oxygen exposure (b1), a small granule within the cell (b2), and the interstitial space (b3). These two representative cells were chosen from multiple cells collected and examined by SEM-EDS. The thin line and the arrows indicate the position of the main sulfur peak in the EDS spectrum.

Scale bar: $25 \mu \mathrm{m}$
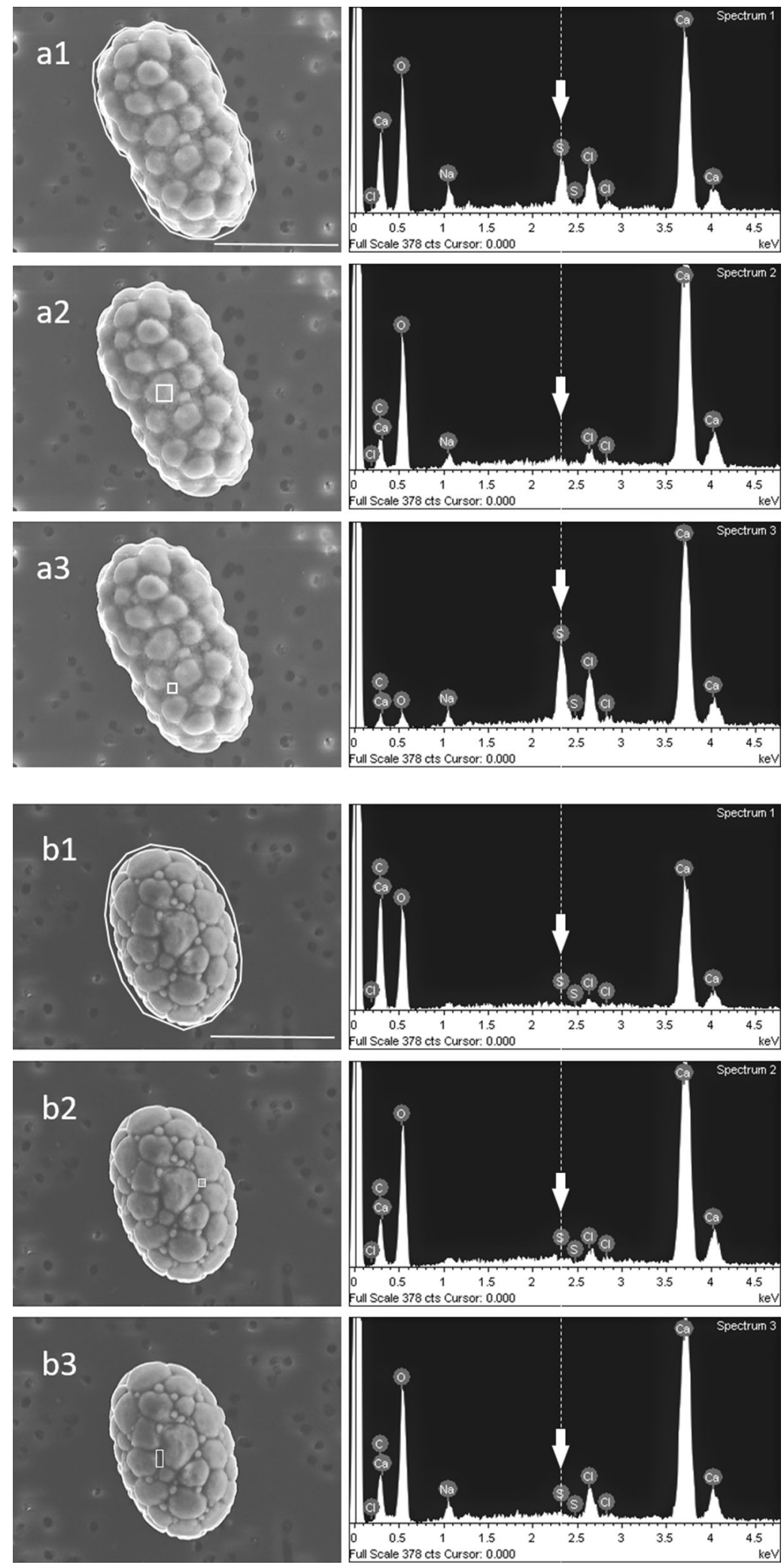
the location of intracellular sulfur cannot be pinpointed with certainty, the results indicate rapid intracellular sulfur depletion after atmospheric oxygen exposure, consistent with the assumption that salt marsh Achromatium can aerobically oxidize sulfur to sulfate (Gray et al. 1997; Salman et al. 2015).

Morphology of intracellular calcite granules

Not only the cellular S:Ca ratio, but also the calcite granule morphology changed in response to atmospheric oxygen exposure. In freshly harvested cells that were not subjected to prolonged oxygen exposure by syringe storage, the granules appeared rough and had bumpy accretions that seemed to extend into and increase the interstitial space that separated the granules from each other (Figs. 4a, S3, S4a, and S5). Achromatium cells that were examined after prolonged air exposure during syringe storage contained smoother granules that appeared more densely packed,
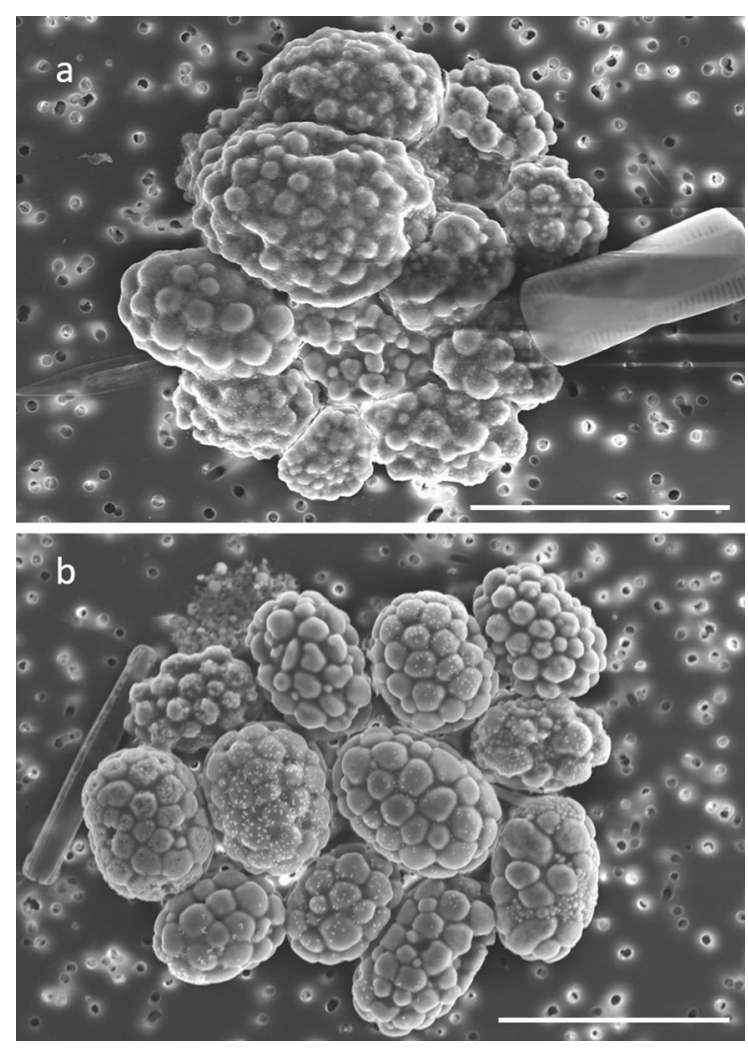

Fig. 4 Morphological differences between cells from surface sediments, freshly collected and not additionally exposed to air (a), and cells that were subsequently exposed to air for $12 \mathrm{~h}$ (b). Scale bar: $50 \mu \mathrm{m}$ and lacked bumpy, irregular accretions. The grooves between the granules appeared to be narrower, and seemed more sharply incised (Figs. 4b, S3, and S4b). This trend was consistent across all cells sampled from surface and subsurface (Fig. S3), suggesting that the artificial exposure to oxygen may be the primary cause for the morphological change observed here.

Focused ion beam (FIB) microscopy was applied to visualize the calcite granules in detail. The formation and accretion scenario based on TEM observations in freshwater Achromatium suggested that the granules are not composed of a single compact calcite crystal, but that they are formed in layers around a central nucleation site (Head et al. 2000). The FIB analysis of bisected calcite granules within a cut-open cell revealed a distinct lamination visible at a micrometer scale (Fig. 5a), as previously reported by Head et al. (2000). Traces of lamination were also observed at the surface of intact calcite granules (Fig. 5b). These observations suggest a scenario of stepwise, biologically controllable accretion and dissolution of calcite layers, consistent with the evidence for colloidal calcite in freshwater Achromatium (West and Griffiths 1913; Gray 2006; Head et al. 2000).

Discussion: a scenario for calcite granule dynamics

The SEM images of Achromatium cells presented here showed distinctly different surface structures for calcite granules under the different treatment conditions, which can be interpreted as growth stages that reflect the successive formation and dissolution of these granules in response to different environmental conditions. Extending earlier observations (Head et al. 2000; Gray 2006), calcite granules are not only composed of laminar structures, but are likely growing by adding new layers at two opposing poles, as indicated by the observation of smaller calcite layers on top of larger ones (Fig. 5). Such a calcite accretion/dissolution mechanism would be required if the observed morphological variety of calcite granules is taken as evidence for systematic morphological changes by granule growth and dissolution. Since this study could not follow the life stages of individual granules, such scenarios have to remain speculative, but they can provide hypothesis-generating context for different granule morphologies, their origin and development. For example, in many freshly processed cells that have 


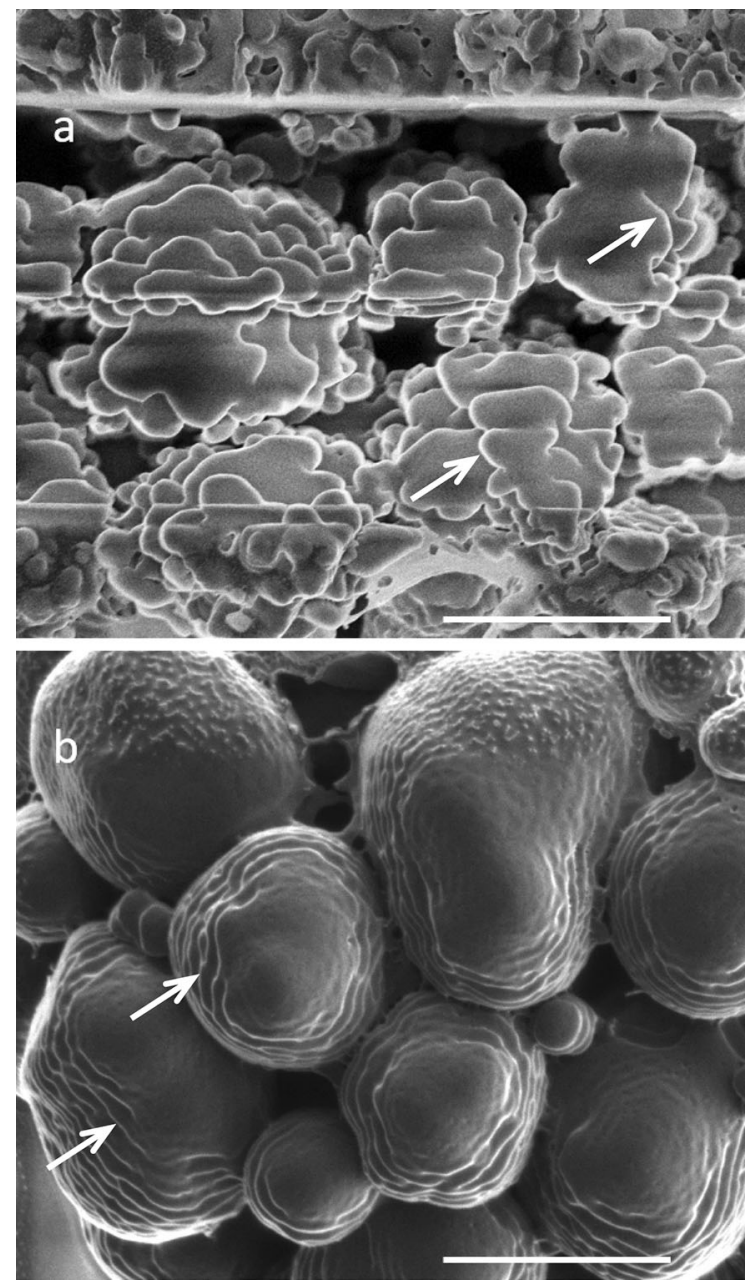

Fig. 5 FIB images of calcite granules in Achromatium cells sampled from surficial sediment, and immediately processed. a The interior laminated structure of calcite granules becomes visible after etching the surface with an ion beam. b Laminations on the outer surface of intact granules. The white arrows point to the laminations. Scale bar: $5 \mu \mathrm{m}$

not undergone prolonged oxygen exposure, small and bumpy accretions were observed on the surface of the calcite granules, combined with a wider interstitial space between the granules (Figs. 4a, S3, S4a). In cells originating from the permanently sulfidic subsurface this rough granule surface was even more pronounced, reminiscent of cauliflower (Fig. S5). We hypothesize that at these sites, calcite could be added to or be removed from an active calcite granule.

In contrast, after prolonged atmospheric oxygen exposure cells showed a strikingly different granule morphology: the cells contained little or no sulfur, but were dominated by compactly packed, large calcite granules with a smooth surface (Figs. 2b, 3b, 4b, S3, and $\mathrm{S} 4 \mathrm{~b}$ ). An ecophysiological interpretation of these observations could follow this outline: Achromatium live within a dynamic oxygen/sulfide gradient and the cells with rough bumpy granules most likely had to react to dynamic redox conditions. The high abundance of "active" calcite granules with bumpy, rough surfaces may thus represent a snapshot of the cell's dynamic reaction and a constant interplay of sulfideand sulfur-oxidation within the cells, especially in the permanently sulfidic subsurface. In cells that were incubated aerobically for over $12 \mathrm{~h}$, we interpret the smooth surface of granules as evidence that the cells were gradually dissolving the granules, starting with the surface bumps and accretions, to buffer the acidity caused by sulfur oxidation. The prolonged exposure to aerobic conditions appears to have triggered a consistent physiological response, forcing the cells to use up their sulfur reservoirs and oxidize it to sulfate; the resulting acidic milieu promotes calcite dissolution, but is also buffered by it.

Supporting indirect evidence for these proposed calcite dynamics is provided by a time-series experiment. Freshly collected Achromatium cells from the sediment surface were placed in oxic salt marsh water, and one cell that remained immotile in the field of view was imaged every $30 \mathrm{~s}$ throughout $17 \mathrm{~h}$. At the beginning of the experiment (Fig. S6), the cell contained few refractive calcite granules. After exposure in oxygen-saturated salt marsh water for $17 \mathrm{~h}$, larger refractive calcite spots emerged in the cell (Figure S6), the corrected total cell fluorescence dramatically increased $36 \%$ (from 328,352 to 447,224 measurement units), but the cell area only enlarged slightly by $2 \%$ (from 6973 to 7129 pixels). Thus, the continuously monitored cell contained more reflective calcite granules, but showed hardly any increase in cell size. Under sulfidic conditions, an Achromatium doubling time of 24-48 h (West and Griffiths 1913) would allow a spherical cell to gain $35 \%$ to $70 \%$ in volume after $17 \mathrm{~h}$, which was not observed here. Instead, the lack of growth under oxygen exposure, combined with increasing reflectivity of the cell, suggests that intracellular calcite globules transition from a bumpy and less reflective towards a smooth and more reflective morphology. This interpretation is consistent with studies linking surface smoothness to increased brightness for many 
rock types, including calcite minerals (Erdogan 2000). Sulfur globules would be oxidized and consumed under these conditions, and are therefore very unlikely to contribute to the increased reflectivity of the oxygen-exposed cell.

To summarize potential stages in the development of individual calcite granules, calcite granule formation could be initiated around a nucleation site, and continue with layered depositions around the outside of the granule that may produce smaller new granules on top of older, larger granules. Finally, the newly accreted layers merge into each other and form smoother, enlarged granules. With respect to the observation that cells from the anoxic subsurface were even more pronounced in this rough surface structure (Figs. S3 and S5), it can be suggested that sulfidic conditions may trigger calcite formation in Achromatium via the here proposed process. Assuming that calcite inclusions do not grow indefinitely, calcite deposition must be balanced either by cell division (with the possible implication that calcite granule extension and formation can precede cell division; see panels with dividing cells in Fig. S3), or calcite deposition must be reversed by dissolution, for example during the acidifying oxidation of elemental sulfur to sulfate (equations IV-VI in the supplementary Online Resource). In our scenario, aerobic conditions cause proton-releasing sulfur oxidation, which leads to calcite dissolution, the gradual erosion of irregular and bumpy granule surfaces, and the production of smooth, rounded granules. As a consequence of granules becoming more smoothly rounded, they might also fit together more tightly and contain smaller interstitial gaps. Only some of the freshly cells collected from the sediment surface showed the conspicuous rough granular surface morphology (e.g. Fig. S3, panel a1); many others had a rather smooth surface, although not as smooth and tightly packed as artificially air-exposed cells (e.g. Fig. S3, panel a3). These cells could be in the process of dynamic calcite formation, since cells from the same saltmarsh pool contained $\mathrm{Ca}^{2+}$-enriched granules (Salman et al. 2015). This heterogeneous mix of fresh surface cells may represent the fact that we collected surface cells from the entire upper $4 \mathrm{~mm}$, which included fully oxic and micro-oxic layers, as well as those layers that just reached anoxia (Fig. S2). We take this observation of cells originating from a dynamic redox layer show varying granular morphologies, while cells from the permanently reduced redox condition have a homogeneous appearance of enhanced roughness as supporting evidence for our hypothesize that granular morphology observed here is a biologically induced dynamic reaction on specific redox regimes.

This interpretation of calcite dynamics is certainly limited by the fact that we were not able to image the different stages of sulfur and calcite turnover within a living Achromatium cell, which would be killed by processing and EDS scanning. Furthermore, we are currently unable to enumerate or identify the different Achromatium genotypes that may coexist in the Sippewissett population (Salman et al. 2015), and while there were reports about the existence of subpopulations of Achromatium that may react or be adapted specifically to certain redox regimes in the sediment column (Gray et al. 1999; Glöckner et al. 1999) our observed trends on calcite morphology and dynamics appear to hold for surface as well as subsurface cells.

A proposed mechanism of calcium and sulfur dynamics in Achromatium

Previous studies suggested that intracellular calcite is used for buoyancy regulation, i.e. the microaerophilic Achromatium cells could sink down into anoxic sediment, or float up to the oxic zone, by calcite precipitation and dissolution (Babenzien 1991). Since the cells at the sediment surface are strongly enriched in calcite, this "anchoring" function could be considered in a different light, i.e. the dense granules anchor the cells within the sediment and prevent their resuspension (Salman et al. 2015). Another presumed function of calcite granules is that their dissolution buffers the acidity generated by aerobic sulfur oxidation to sulfate (La Rivière and Schmidt 1992; Salman et al. 2015). Our results indicate that the intracellular dynamics of sulfur and calcite are regulated in a more complex manner. During microoxic or anoxic, sulfidereplete conditions, the cells take up sulfide and oxidize it only to the stage of elemental sulfur (Salman et al. 2015). The resulting elemental sulfur is deposited intracellularly, and the S:Ca ratio increases, consistent with our experimental results that show the highest S:Ca ratios in freshly processed Achromatium cells from subsurface sediments (Fig. 1, Table S1). The process of sulfide oxidation to elemental sulfur 
consumes protons, increasing the intracellular $\mathrm{pH}$ (Equations I to III, Supplementary Online Resource), and thus improving the conditions for calcite precipitation. Given the precision and rapid dynamic of calcite deposition and dissolution it can be speculated that the processes are biologically controlled (Gray 2006), i.e. enzymatically. While an intracellular $\mathrm{pH}$ increase may help trigger the process, the high $\mathrm{pK}$ value (10.32) of the bicarbonate/carbonate equilibrium indicates that alkalinity in itself is insufficient to directly induce calcite precipitation and granule growth; instead a membrane surrounding the granule may play a role in controlling precipitation (Salman et al. 2015). We propose that the small granular deposits observed at the periphery of existing calcite granules (Figs. S3, S5) represent accretion stages during granule growth, and result in the formation of larger calcite granules. The small $\mathrm{Ca}^{2+}$-rich deposits detected here and previously (Salman et al. 2015) are tightly packed into the interstitial space between the large calcite inclusions, and they possibly provide a calcium reservoir for biologically mediated calcite precipitation without substantially changing the overall calcium content of the cell.

When a suitable electron acceptor is abundantly available, elemental sulfur is oxidized to sulfate, generating protons in the process (Equations IV to VI, Supplementary Online Resource). In nature, daytime photosynthesis generates oxygen as the main electron acceptor at the sediment surface, and oxygen-rich conditions were experimentally induced here by prolonged air-exposure. Since sulfate is easily soluble and is typically exported from the cell, the intracellular $\mathrm{S}: \mathrm{Ca}$ ratios should reach their minimum during oxygen exposure, consistent with our experimental results (Table S1). The protons that are generated during the oxidation of intracellular sulfur to sulfate could subsequently be buffered by calcite dissolution and bicarbonate $\left(\mathrm{HCO}_{3}{ }^{-}\right)$formation (La Rivière and Schmidt 1992; Salman et al. 2015). We hypothesize that, in analogy to calcite precipitation, the calcite dissolution process is also initiated at the periphery of the granules; gradual calcite erosion appears to be reflected in the observed smooth, rounded surface morphology during aerobic conditions, both, naturally (e.g. Fig. S3a3) and artificially induced (Figs. 2b, 3b, $4 \mathrm{~b}, \mathrm{~S} 3$, and S4b). Most recently, a study on grazers of Achromatium in freshwater Lake Stechlin in Germany noticed that meiofaunal predators only hunt the smallest Achromatium cells and store them in their low-pH food vacuoles, presumably for calcite dissolution (Schorn and Cypionka 2018). Apparently, hardto-digest calcite inclusions combined with large cell size provides Achromatium with some protection against meiofaunal grazing.

\section{Summary and outlook}

The results of this study support and extend previously proposed survival strategies of Achromatium cells under different redox conditions and sulfur oxidation regimes (Head et al. 2000; Salman et al. 2015). Sulfide and sulfur oxidation provide energy, which the cell uses for transporting physiologically important ions, including $\mathrm{H}^{+}$and $\mathrm{Ca}^{2+}$. The internal calcite pool buffers the intracellular $\mathrm{pH}$ fluctuations linked to two alternative physiological states (electron acceptor limitation during sulfide oxidation to sulfur, which consumes protons, and electron acceptor abundance during sulfur oxidation to sulfate, which produces protons) that an active Achromatium cell would experience during a diurnal cycle in surficial sediments. Since the draft genomes of three Achromatium populations from a brackish warm spring (Mansor et al. 2015), a marine Achromatium cell from Sippewissett tidal pools (Salman et al. 2016), and multiple freshwater Achromatium genomes from Lake Stechlin have been assembled (Ionescu et al. 2017), comparative genome annotation of multiple Achromatium populations becomes possible, and allows to identify pathways and genes that are specifically relevant for members of this genus. Based on these findings, expression patterns of key genes in Achromatium could be linked to physiological observations under defined environmental regimes. Here, physiological adaptations to changing redox regimes and also to $\mathrm{pH}$ fluctuations in the external milieu could be of particular interest. For example, daytime extremes of photosynthetic oxygen abundance in the Achromatium-rich phytodetrital layer in the Sippewissett tidal pools coincide with $\mathrm{pH}$ 9, as a result of photosynthetic $\mathrm{CO}_{2}$ limitation in situ (Salman et al. 2015). The fine-tuned system of intracellular calcite and sulfur dynamics will require further investigation in the light of such pronounced environmental gradients. 
Acknowledgements This study was initiated during the 2013 Microbial Diversity Course, Marine Biological Laboratory, Woods Hole, MA. We thank the course directors, Dr. Dan Buckley and Dr. Steve Zinder, as well as all assistants for their tremendous support. TY received the Horace W. Stunkard Scholarship and a post-course fellowship from MBL, and was supported further by a visiting student fellowship at Aarhus University to perform the microelectrode measurements. We thank Lars Borregaard Pedersen and Preben Grann Sørensen for their great help in the microsensor lab at Aarhus University. We also thank Dr. Virginia Edgcomb from Woods Hole Oceanographic Institution for her tremendous help on sampling.

Authors' contributions TY took samples, did SEM-EDS, analysed data and wrote the first versions of the manuscript. AT assisted with the incubation experiment, revised the manuscript, and provided advice on data interpretation. WA helped with SEM-EDS, performed FIB, and provided suggestions. RB worked on overnight cell observation and provided good method suggestions. VS-C assisted with fieldwork, provided advice on data interpretation, and revised the manuscript. LPN mentored the microelectrode experiment.

Conflict of interest The authors declare that they have no conflict of interest.

\section{References}

Babenzien HD (1991) Achromatium oxaliferum and its ecological niche. Zentralbl Mikrobiol 146:41-49

Cossy J, Pale P (1987) Silylation selective par L'Hexamethyldisilazane. Tetrahedron Lett 28:6039-6040

Erdogan M (2000) Measurement of polished rock surface brightness by image analysis method. Eng Geol 57:65-72

Glöckner FO, Babenzien HD, Wulf J, Amann R (1999) Phylogeny and diversity of Achromatium oxaliferum. Syst Appl Microbiol 22:28-38

Gray ND (2006) The unique role of intracellular calcification in the genus Achromatium. In: Shiverly JM (ed) Inclusions in Prokaryotes. Microbiol. Monographs 1. Springer, Berlin, pp 299-309

Gray ND, Head IM (2014) The family Achromatiaceae. In: Rosenberg E, DeLong EF, Lory S, Stackebrandt E, Thompson FL (eds) The Prokaryotes: Gammaproteobacteria. Springer, Berlin, pp 1-14

Gray ND, Pickup RW, Jones JG, Head IM (1997) Ecophysiological evidence that Achromatium oxaliferum is responsible for the oxidation of reduced sulfur species to sulfate in a freshwater sediment. Appl Environ Microbiol 63:1905-1910

Gray ND, Howarth R, Pickup RW, Gwyn Jones J, Head IM (1999) Substrate uptake by uncultured bacteria from the genus Achromatium determined by microautoradiography. Appl Environ Microbiol 65:5100-5106
Head IM, Gray ND, Clarke KJ, Pickup RW, Jones JG (1996) The phylogenetic position and ultrastructure of the uncultured bacterium Achromatium oxaliferum. Microbiology 142:2341-2354

Head IM, Gray ND, Howarth R, Pickup RW, Clarke KJ, Jones JG (2000) Achromatium oxaliferum-understanding the unmistakable. In: Schink B (ed) Advances in Microbial Ecology, vol 16. Kluwer Academic/Plenum Publishers, New York, pp 1-40

Ionescu D, Bizic-Ionescu M, De Maio N, Cypionka H, Grossart HP (2017) Community-like genome in single cells of the sulfur bacterium Achromatium oxaliferum. Nat Commun 8:455. https://doi.org/10.1038/s41467-017-00342-9

La Rivière JWM, Schmidt K (1992) Morphologically conspicuous sulfur-oxidizing Eubacteria. In: Trüper HG, Dworkin M, Harder W, Schleifer KH, Balows A (eds) The Prokaryotes. Springer, New York, pp 3934-3947

Lauterborn H (1915) Die sapropelische Lebewelt. Ein Beitrag zur Biologie des Faulschlamms natürlicher Gewässer. Verhandl Naturhistor Mediz Ver Heidelberg 13:395-481

Mansor M, Hamilton TL, Fantle MS, Macalady J (2015) Metabolic diversity and ecological niches of Achromatium populations revealed with single-cell genomic sequencing. Front Microbiol 6:822. https://doi.org/10.3389/fmicb. 2015.00822

Pellegata R, Pinza M, Pifferi G (1978) An improved synthesis of $\gamma-, \delta$-, and $\varepsilon$-Lactams. Synthesis 8:614-616

Salman V, Yang T, Berben T, Klein F, Angert E, Teske A (2015) Calcite-accumulating large sulfur bacteria of the genus Achromatium in Sippewissett Salt Marsh. ISME J 9:2503-2514

Salman V, Berben T, Bowers RM, Wojke T, Teske A, Angert E (2016) Insights into the single cell draft genome of Candidatus "Achromatium palustre". Stand Genom Sci 11:28. https://doi.org/10.1186/s40793-016-0146-X

Schneider CA, Rasband WS, Eliceiri KW (2012) NIH Image to ImageJ: 25 years of image analysis. Nat Methods 9:671-675

Schorn S, Cypionka H (2018) A crispy diet: grazers of Achromatium oxaliferum in Lake Stechlin Sediments. Microbial Ecology. https://doi.org/10.1007/s00248-018-1158-4. [Epub ahead of print]

Seitz AP, Nielsen TH, Overmann J (1993) Physiology of purple sulfur bacteria forming macroscopic aggregates in Great Sippewissett salt marsh, Massachusetts. FEMS Microbiol Ecol 12:225-236

Steudel R (2003) Aqueous Sulfur Sols. Top Curr Chem 230:153-166

West GS, Griffiths BM (1913) The lime-sulphur bacteria of the genus Hillhousia. Ann Bot 27:83-91

Wilbanks EG, Jaekel U, Salman V, Humphrey PT, Eisen JA, Facciotti MT, Buckley DH, Zinder SH, Gruschel GK, Fike DA, Orphan VJ (2014) A sulfurous symbiosis: microscale sulfur cycling in the pink berry consortia of the Sippewissett salt marsh. Environ Microbiol 16:3398-3415 